\title{
Variability of Blowing Dust Weather Frequency over Semi-Arid Areas of China (Baicheng, Jilin Province) and Relationships with Climatic Factors During 1951 - 2006
}

\author{
Yun-Fei $\mathrm{Wu}^{1,2}$, Ren-Jian Zhang ${ }^{1, *}$, Cong-Bin $\mathrm{Fu}^{1}$, and Zong-Ting Gao ${ }^{3}$ \\ ${ }^{1}$ Key Laboratory of Regional Climate-Environment Research for Temperate East Asia, \\ Chinese Academy of Sciences, Beijing, China \\ ${ }^{2}$ Graduate University, Chinese Academy of Sciences, Beijing, China \\ ${ }^{3}$ Jilin Meteorological Science Institute, Changchun, China
}

Received 1 March 2010, accepted 15 September 2010

\begin{abstract}
We analyzed the variability of blowing dust weather frequency (BDWF) and patterns in climatic factors over Baicheng for the period 1951 - 2006 in this study. The data showed that blowing dust over Baicheng occurs intensively during the spring and shows significant inter-decadal variability. One of the main findings is that the occurrence of blowing dust has significantly decreased after the mid-1980s. The mean wind speed (WS), diurnal temperature range (DTR), relative humidity (RH) and precipitation at Baicheng during the spring show decreasing trends. The decreasing trends of the mean WS and DTR are significant at $99 \%$ confidence levels according to the t-test; the dataset also indicated a sharp decrease in WS occurred after the mid-1980s. The mean surface air temperature (SAT) escalated in a fluctuating manner during $1951-2006$. BDWF at Baicheng was significantly related to local WS, SAT and DTR during the spring [correlation coefficients (CCs) are $0.41,-0.47$ and 0.36, respectively]. The correlation between BDWF at Baicheng and selected climatic factors over the sand-dust source regions and transmission paths were also calculated. We found that BDWF is well correlated to the mean WS and SAT during the spring, with CCs of 0.45 and -0.48 , respectively. The most likely causes for the dramatic decrease observed in BDWF after the mid-1980s were related to the adjustment of large-scale circulation patterns in response to a decrease of meridional temperature differences, the weakening of steering westerlies and the strengthening of downward motions that has occurred at the middle latitudes of eastern Eurasia in recent decades.
\end{abstract}

Key words: Blowing dust weather frequency, Climatic factors, Variability, relationship

Citation: Wu, Y. F., R. J. Zhang, C. B. Fu, and Z. T. Gao, 2011: Variability of blowing dust weather frequency over semi-arid areas of China (Baicheng, Jilin Province) and relationships with climatic factors during 1951 - 2006. Terr. Atmos. Ocean. Sci., 22, 315-324, doi: 10.3319/TAO.2010.09.15.01(A)

\section{INTRODUCTION}

Dust carried by high winds, especially as dust storms, are one of the main disastrous weather phenomenon affecting northern China. When dust events such as dust storms occur, the suspended particles in the atmosphere dramatically increase, resulting in decreased visibility. Dust storms can greatly affect normal social activities and are hazardous for human health. The Chinese government has taken many measures to reduce the occurrence and transmission of dusty weather such as reconverting farmland to grassland and planting trees in arid areas. Although these human

\footnotetext{
* Corresponding author

E-mail:zrj@mail.iap.ac.cn
}

measures have impacts on the frequency of dusty weather to some degree, the occurrence of dusty weather depends more on the variation in natural conditions such as climatic factors. It is therefore important to conduct research on the variability of dust weather frequency (DWF), climatic factors and their relationships.

In recent years, many studies with regard to the occurrence of dusty weather in East Asia have been conducted using statistical analyses of ground observations, model simulations and remote sensing. These studies have include long time-scale statistical analyses of dust weather over whole China or over large fields such as north part of China (Qiu et al. 2001; Zhou 2001; Qian et al. 2002; Zhou and 
Zhang 2003; Wang et al. 2008), short time-scale analyses of dusty weather over a single station or over a small area $(\mathrm{Li}$ and Gao 2001; Fan and Wang 2004, 2007; Jiao et al. 2004; Zhang et al. 2005), and case studies regarding the conditions that promote the occurrence of dusty weather and influence transport paths (Wang et al. 2000; Gao et al. 2004; Liu et al. 2004). Some research has also been carried out on the physical and chemical characteristics of particulate matter that is transported during time periods associated with dusty weather in East Asia (Liu and Shiu 2001; Han et al. 2004; Zhang et al. 2005, 2009; Shen et al. 2007). Liu et al. (2007) conducted research on the variability of DWF over Beijing and snow coverage in sand-dust source regions and found that the depth and range of the snow coverage in sand-dust source regions was significantly and negatively correlated with DWF over Beijing. Fan and Wang (2004) found that the DWF in northern China might be closely related with the Antarctic Oscillation. However, these studies were either too general or only focused on populated regions such as Beijing. Few studies have focused on the dusty weather that occurs over the special region investigated in this study (Baicheng, Jilin province, northeast China), except for studies on the composition of particulate matter during a short experimental period (Zhang et al. 2008). Baicheng is located in the intermediate zone between arid and semiarid areas (Fig. 1) and the marginal areas influenced by the East Asian Monsoon (EAM), which is a sensitive region for global change. The variations of some factors in this region, such as DWF, wind and temperature, can reflect trends in regional and global climate change. For instance, variation in DWF can reflect variation of EAM to some degree $(\mathrm{Wu}$ et al. 2010). Thus, to understand the climate change in this region more fully, variability in DWF over Baicheng, patterns in some climatic factors, and the relationships between these two will be discussed. The possible causes for the variations, especially inter-decadal variations, will also be investigated by analyzing variations in large-scale circulations in eastern Eurasia.

\section{DATA}

The monthly DWF data over Baicheng for the period between 1951 - 2006 are derived from the China Meteorological Administration (CMA). Generally, the dust weather fit into three categories: dust storm weather, blowing dust weather and floating dust weather. If an ensemble of particles of dust is energetically lifted to great heights by a strong and turbulent wind with a horizontal visibility of less than $1 \mathrm{~km}$, it is called dust storm weather, and if dust is raised by moderate winds to moderate heights above the ground with a horizontal visibility in the range of $1-10 \mathrm{~km}$, it is called blowing dust weather. Finally, if dust is raised by weak winds to a low height above the ground with a horizontal visibility of less than $10 \mathrm{~km}$, it is called floating (or drifting) dust weather. Obviously, visibility is a primary criterion for distinguishing these three types of dust weather. The measuring of visibility is influenced by artificial factors to some degree, so the record of dust weather may be influenced by human factors and may iterate the record of several kinds of dust weather. Also, as compared to blowing dust weather,

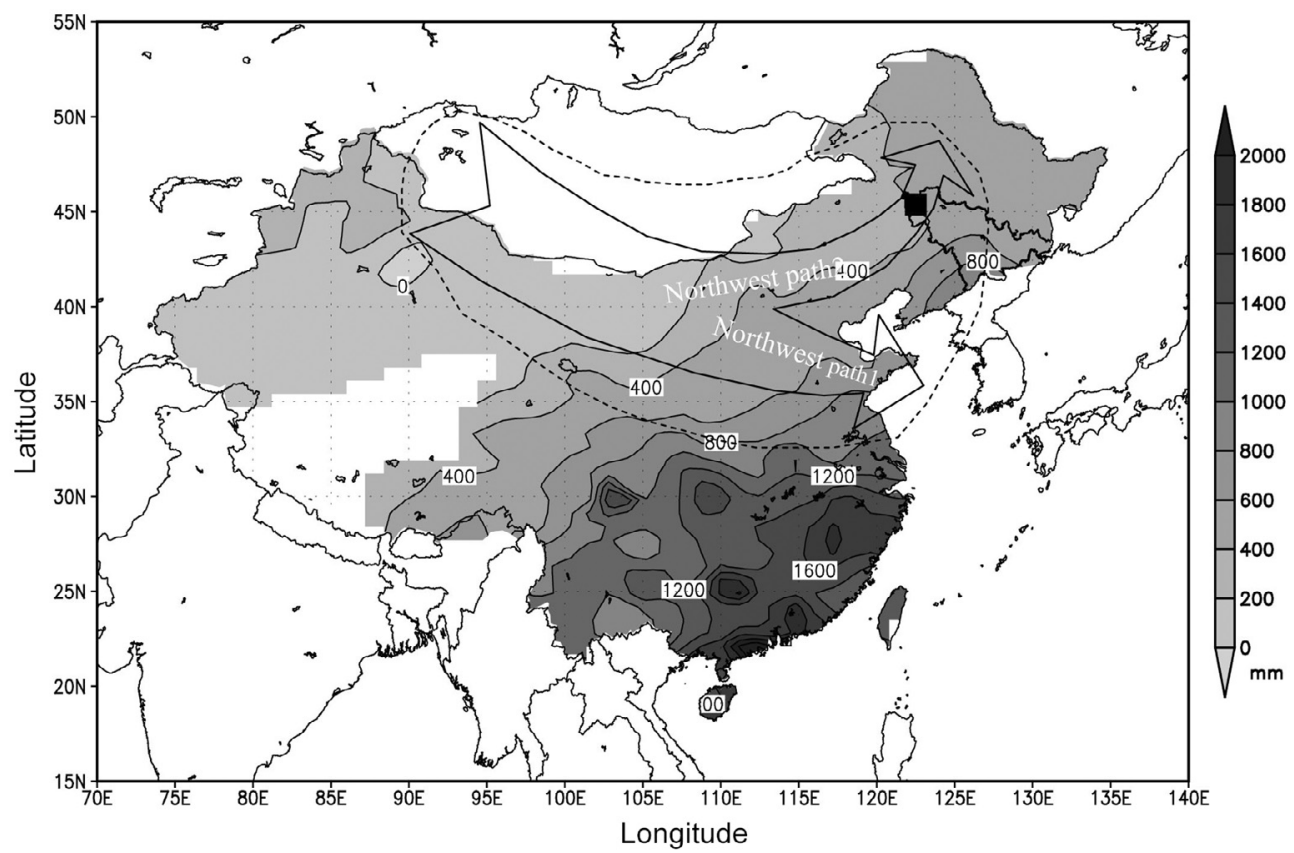

Fig. 1. Distribution of annual precipitation averaged for the period of 1960 - 2008 and the northwest path of dust weather influencing China. The dark solid square is the location of Baicheng, and the areas contained in the dashed curve are the influencing areas of northwest path. 
the other two dust weather types (dust storm and floating dust weather) rarely occurred over Baicheng (Fig. 2). Thus, the analysis below is mainly limited to the most representational blowing dust weather.

The daily datasets, including the mean wind velocity, mean, maximum and minimum surface air temperature, mean relative humidity, and the monthly datasets of precipitation of 75 observation stations in the areas that ranged from $40-45^{\circ} \mathrm{N}$ and $95-125^{\circ} \mathrm{E}$ for the period of $1951-2006$ from CMA are also used in the study. Moreover, re-analysis datasets of the monthly mean surface air temperatures, wind speeds, geo-potential heights and vertical velocities for the period of 1950 - 2006 that were derived from the National Centers for Environmental Prediction-National Center for Atmospheric Research (NCEP/NCAR) are also used (Kalnay et al. 1996).

All of the above-mentioned data are averaged for the seasons, such as the winter months (December, January and February, or DJF) and the spring months (March, April and May, or MAM).

\section{RESULTS}

\subsection{Variability of Blowing Dust Weather Frequency (BDWF) over Baicheng}

The inter-seasonal variability of BDWF generally occurs as three types of events: (1) occurs mostly during the spring, (2) mostly during the late winter and early spring, and (3) occurs frequently during the spring and summer (Zhou 2001). In Fig. 3a, it is evident that the inter-seasonal variability of BDWF over Baicheng typically belongs to the first type or mostly occurring in the spring. The proportion of BDWF in the spring as related to the total BDWF is about $75 \%$ during the period of 1951 - 2006, with a maximum value of $33 \%$ occurring in April. The inter-seasonal variability of BDWF is well related to the active cold air, strong wind forces, dry air and rising temperature in northern China during the spring (Zhou 2001; Zhang et al. 2002). Because the blowing dust weather over Baicheng is concentrated in the spring, the following study will focus on investigating the variability of the BDWF during the spring (BDWF-MAM) and its relation to some climatic factors.

The inter-annual variability of BDWF-MAM over Baicheng for the period of 1951 - 2006 is shown in Fig. 3b. The BDWF-MAM clearly presents a decreasing trend (with a confidence level of $99 \%$ from a standard student's t-test) and an inter-decadal variability during the selected period. From the 11-point moving average curve in Fig. 3b, it can be found that blowing dust weather occurs most frequently in the 1950s (especially during the mid-1950s). The BDWF decreases after the 1960 s. Another relatively frequent occurrence of the BDWF appears in the period from 1970 to the early 1980s. After the mid-1980s, the BDWF over

(a)
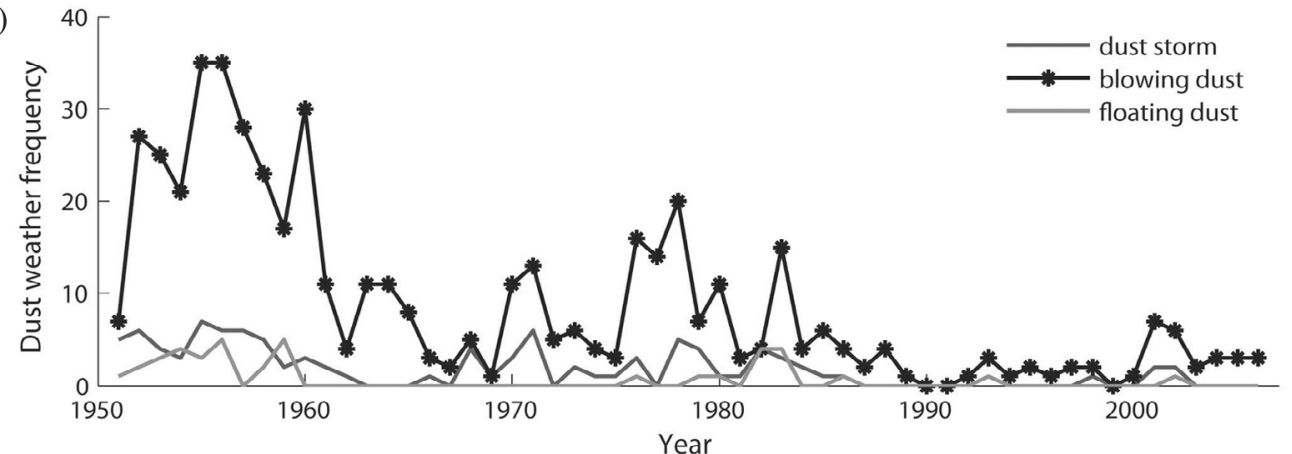

(b)

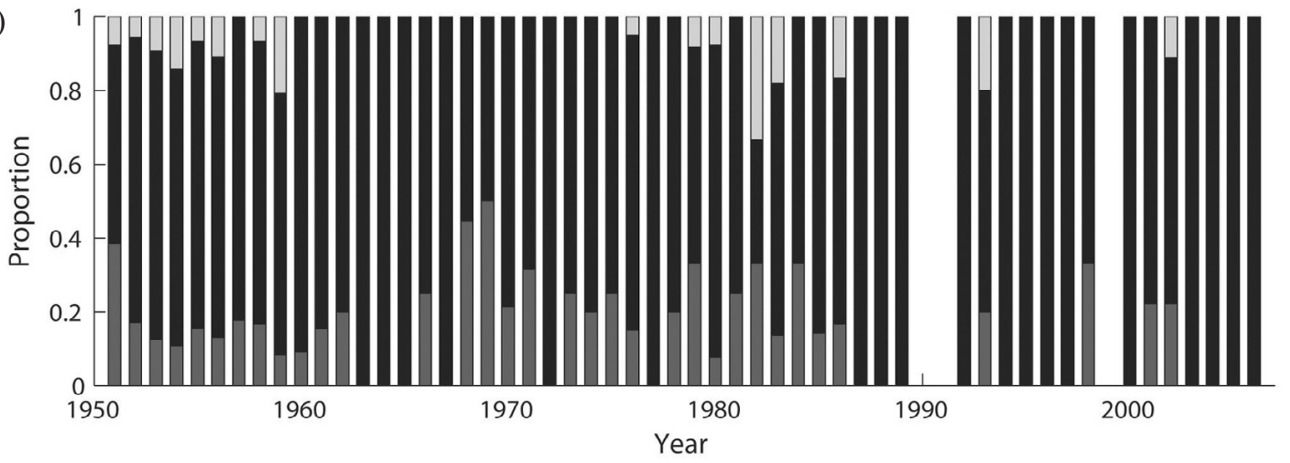

Fig. 2. (a) Time series of annual dust storm weather frequency (dark gray solid line), blowing dust weather frequency (black and marked line) and floating dust weather frequency (light gray solid line) over Baicheng, for the period of 1951 - 2006; (b) the proportions of these three dust storm weather frequency of each year (dust storm: dark gray; blowing dust: black; floating dust: light gray). 

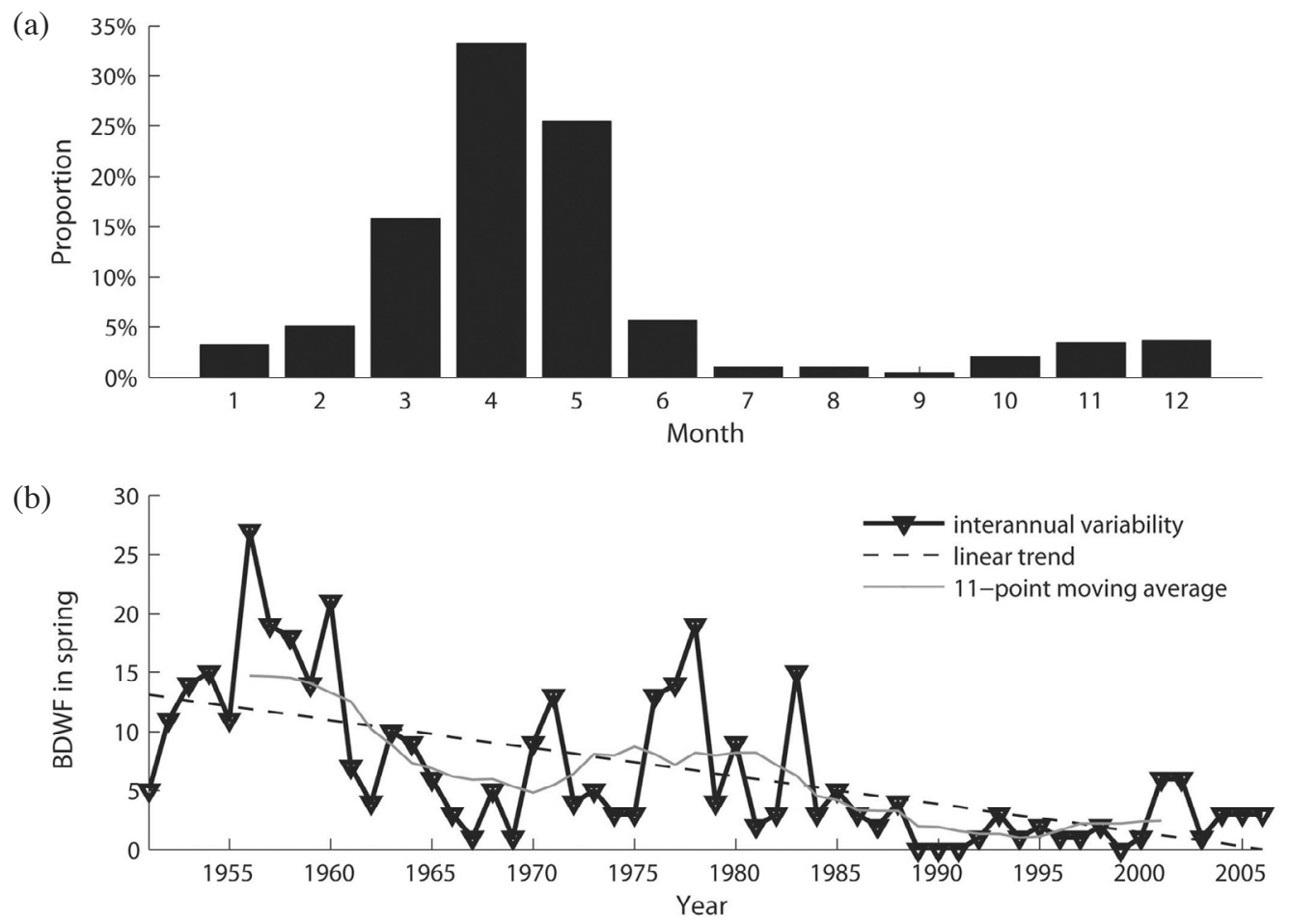

Fig. 3. (a) Proportions of monthly BDWF over Baicheng normalized by the total BDWF during the period of 1951 - 2006; (b) time series of BDWF (in days) over Baicheng during the spring (dark solid and marked), its linear trend (dashed) and 11-point moving average curve (gray solid), for the period of $1951-2006$.

Baicheng becomes very low, only with a small increase in the first two to three years of the $21^{\text {st }}$ century.

\subsection{Variability of Some Climatic Factors over Baicheng}

The inter-annual variability of the six climatic factors, including the mean wind speed (WS), mean surface air temperature (SAT), mean diurnal temperature range (DTR), mean relative humidity ( $\mathrm{RH})$ and precipitation, as well as the BDWF over Baicheng during the spring, is shown in Fig. 4. It can be clearly seen that all of these variables during the spring, except for the mean SAT, present decreasing trends more or less for the period of 1951 - 2006. Among them, the decreasing trends of the mean WS and DTR during the spring are significant (with confidence levels of 99\%). The mean WS over Baicheng during the spring does not change much from the late 1950s to the late 1970s, and almost remains the same at $5 \mathrm{~m} \mathrm{~s}^{-1}$. However, it presents a strong decreasing trend after the late 1970s, especially after the mid-1980s, and then is nearly below $4 \mathrm{~m} \mathrm{~s}^{-1}$ (Fig. 4b). The inter-decadal variation of the mean WS during the spring is consistent with that of the BDWF-MAM to some degree, both of which have been sharply decreasing since the mid-1980s. The mean SAT over Baicheng in the spring escalates in a fluctuating manner with significant inter-annual variation for the period of 1951 - 2006 (Fig. 4c), which corresponds to the activities of global warming (Lashof and
Ahuja 1990; Cox et al. 2000; Root et al. 2003). "DTR" here means the SAT difference between the daily maximum and minimum values. The mean DTR in the spring presents a sustained decreasing trend with significant inter-annual variation during the chosen period (Fig. 4d). The variation of the mean DTR may mean that the stability of atmospheric stratification declines during this period. Although the mean relative humidity $(\mathrm{RH})$ in the spring shows a decreasing trend, the decrease mainly occurs before the mid1960s. Then, the mean RH almost remains the same at $40 \%$ (Fig. 4e). Because Baicheng is situated in arid/semi-arid areas, the precipitation is concentrated during the summer. The rainfall over Baicheng in the spring is very little, being around $50 \mathrm{~mm}$, and its tendency is not significant, with only slight decreasing trends for the period of $1951-2006$ (Fig. 4f).

The variability of these climatic factors shown above has given a general sense of the climate change features in this region. The relationship between the BDWF and these climatic factors during the spring will be studied below as the other focal point of this paper.

\subsection{Relationship Between the BDWF and the Climatic Factors}

The correlation coefficients (CCs) between the BDWFMAM and the climatic factors mentioned above over Ba- 
icheng during the spring are listed in Table 1. It can be clearly found that the BDWF-MAM correlates positively with the mean WS and DTR, and negatively with the mean SAT over Baicheng during the spring. The CCs between the BDWFMAM and the mean RH and precipitation during the spring are not significant. This means that there may be possible corresponding relationships between the BDWF-MAM and the mean WS, SAT and DTR over Baicheng during the spring.

It is well-known that there are three essential conditions for the occurrence of dust weather: strong and enduring gusts of wind, sufficient sand-dust, and unstable weather (Hu and Mitsuta 1997; Li and Gao 2001; Zhang et al. 2003). Actually, the maximum WS would be the better choice for our purposes to investigate its relation with DWF, but the dataset of the daily maximum WS is incomplete and discontinuous for the study period of 1951 - 2006. Therefore, the dataset of the daily mean WS can only be used here. Moreover, the correlation coefficient between the mean WS and the days of maximum WS greater than $10 \mathrm{~m} \mathrm{~s}^{-1}$ over Ba- icheng during the spring reaches a value of up to 0.82 . This means that the mean WS can represent the gale frequency well to a high extent. Both the BDWF and the mean WS over Baicheng in the spring significantly decrease during the chosen period, and show more sharply decrease after the mid-1980s (Figs. 4a and b). This trend may mean that weakening wind suppresses the dynamic condition for dust weather, and results in a decrease of the BDWF. Many studies have shown that the DWF was strongly related to cold temperature anomalies during the cold seasons (Qian et al. 2002; Zhang et al. 2002). Therefore, the sustained increase of SAT during this time (inter-annual variability of SAT during the winter was not shown) may have some impact on the decrease in BDWF. The DTR is a possible index of atmospheric stability; its decrease may affect another condition of dust weather: instability or unstable weather, and may also reduce the BDWF.

However, the occurrences of dust weather events are not only related to local meteorological conditions, but they (a)

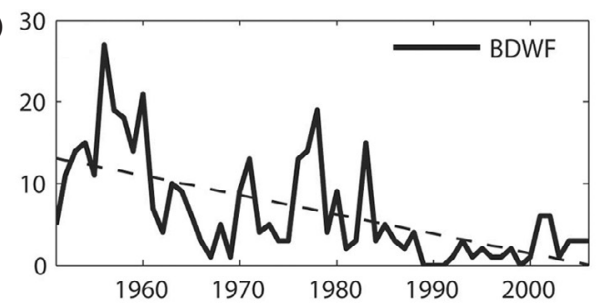

(c)

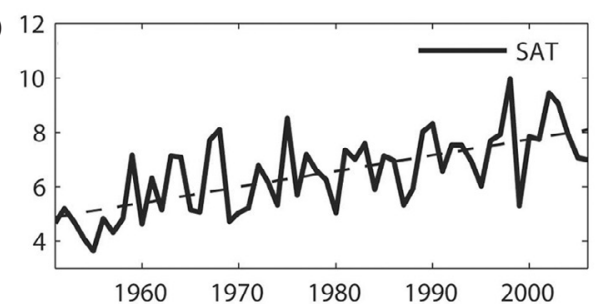

(e)

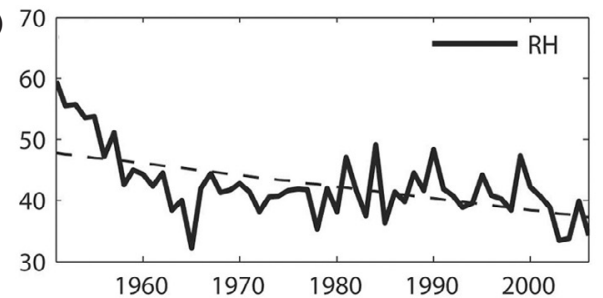

(b)

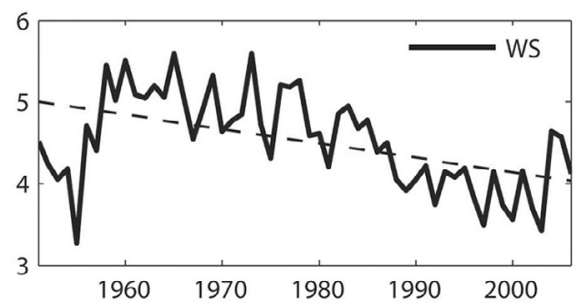

(d)

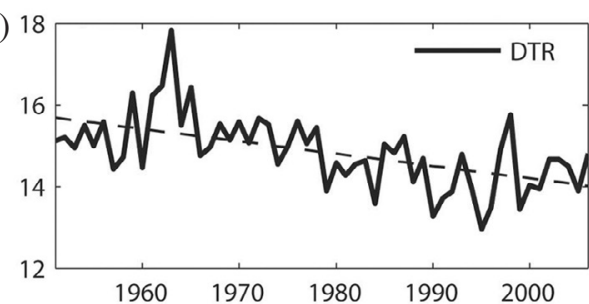

(f)

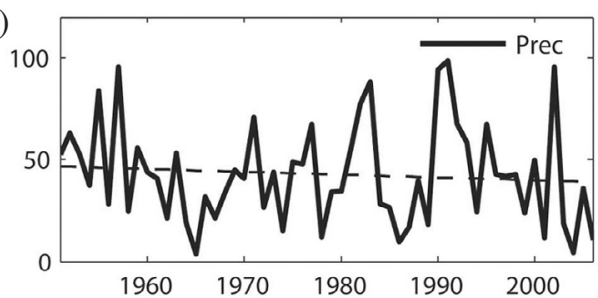

Fig. 4. Time series of (a) BDWF, (b) mean wind speed, (c) mean surface air temperature, (d) mean diurnal temperature range, (e) mean relative humidity, and (f) precipitation over Baicheng during the spring for the period of 1951 - 2006; the dashed line in each sub-Figure corresponds to its linear trend. Units are days, $\mathrm{m} \mathrm{s}^{-1},{ }^{\circ} \mathrm{C},{ }^{\circ} \mathrm{C}, \%$, and mm, respectively, for (a), (b), (c), (d), (e), and (f).

Table 1. The correlation coefficients between the BDWF-MAM over Baicheng and local climatic factors during the spring.

\begin{tabular}{cccccc}
\hline & Mean wind speed & $\begin{array}{c}\text { Mean air } \\
\text { temperature }\end{array}$ & $\begin{array}{c}\text { Mean diurnal } \\
\text { temperature range }\end{array}$ & $\begin{array}{c}\text { Mean relative } \\
\text { humidity }\end{array}$ & precipitation \\
\hline BDWF-MAM & $0.41^{*}$ & $-0.47^{*}$ & $0.36^{*}$ & 0.25 & 0.13 \\
\hline
\end{tabular}

* Indicates that the correlation coefficients are significant at $99 \%$ confidence levels from the $t$-test. 
also largely depend on meteorological conditions in sanddust source regions and transmission paths. Generally, there are three main pathways for dust weather events influencing China: the northwest path (including northwest paths 1 and 2, as shown in Fig. 1), west path and north path, which are similar to the pathways of the cold air invading China. Among these pathways, Northwest Path 2 is the primary dust weather's path affecting Baicheng, which originates from southern Mongolia and central-western Inner Mongolia, and mainly influences the eastern part of Northwest China, the northern part of North China and most of Northeast China. The relationship between the BDWF-MAM over Baicheng and the climatic factors over the sand-dust source and transmission path regions of Northwest Path 2 during the spring is also studied here due to what has been discussed above regarding the relationship between the BDWF-MAM and local climatic factors.

Seventy-five observation stations on the Northwest Path 2 are chosen (range of $40-45^{\circ} \mathrm{N}, 95-125^{\circ} \mathrm{E}$ ) and the mean values of the mean WS, SAT, DTR, RH and precipitation of these 75 stations during the spring are calculated. Their time series for the period of 1951 - 2006 are shown in Fig. 5. It is not difficult to find that the variability in the chosen climatic factors that is averaged by these 75 stations is very similar to that over Baicheng (Figs. 4 and 5). The CCs between the BDWF-MAM of Baicheng and the averaged climatic factors of these 75 stations during the spring are listed in Table 2. It can be clearly found that the CCs are also similar to those between the BDWF-MAM over Baicheng and the local climatic factors, only with the correlation coefficient between the BDWF-MAM and mean DTR changing from being significant to being insignificant (with a 99\% confidence level). As discussed above, the significant positive correlation coefficient between the BDWFMAM and mean WS may mean that the BDWF decreasing is related to the wind weakening in the sand-dust source and transmission path regions. The significant negative correlation coefficient between the BDWF-MAM and mean SAT (a)

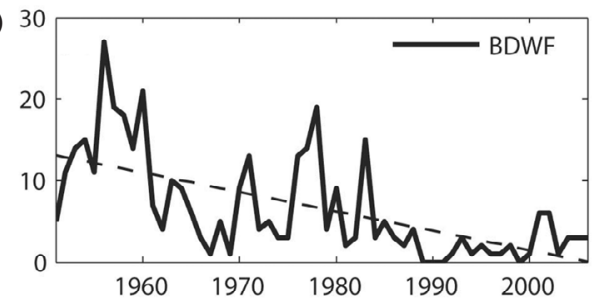

(c)

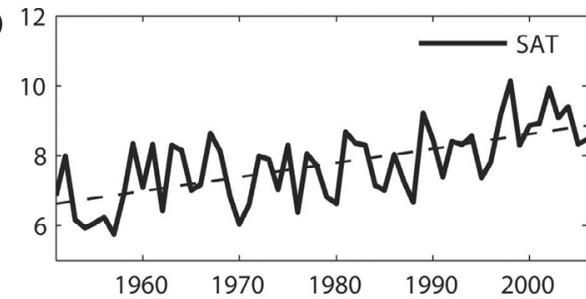

(e)

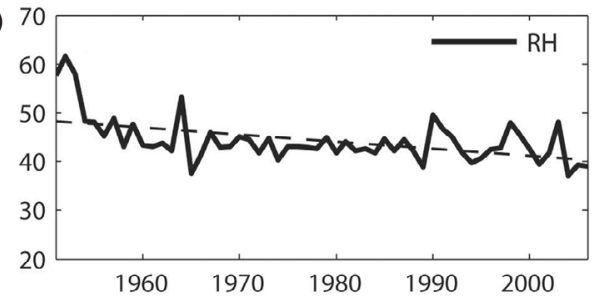

(b)

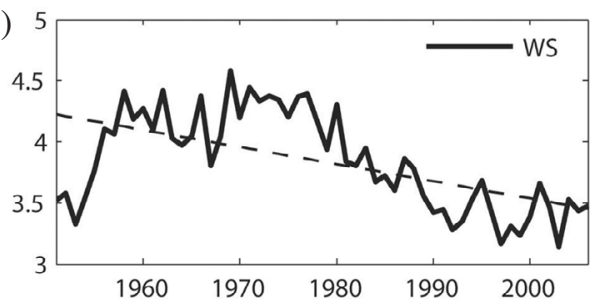

(d) 1

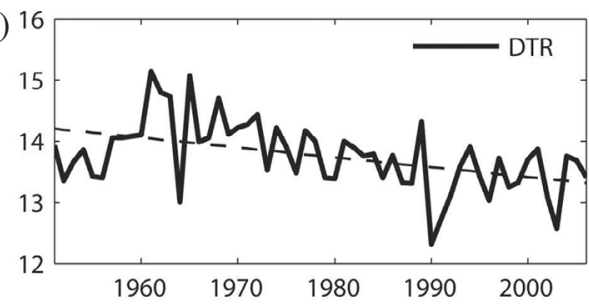

(f)

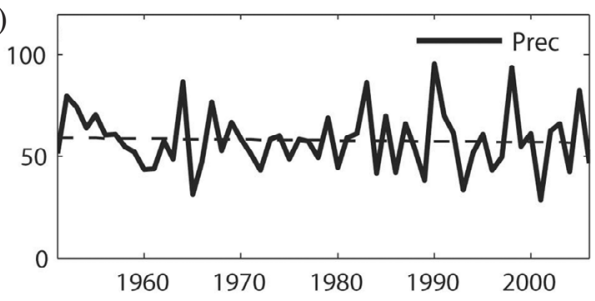

Fig. 5. The same as Fig. 4, but for the mean of 75 observation stations over the areas ranging from $40-45^{\circ} \mathrm{N}, 95-125^{\circ} \mathrm{E}$, for the period of $1951-$ 2006.

Table 2. The correlation coefficients between the BDWF-MAM over Baicheng and mean climatic factors of the selected 75 observation stations during the spring.

\begin{tabular}{cccccc}
\hline & Mean wind speed & $\begin{array}{c}\text { Mean air } \\
\text { temperature }\end{array}$ & $\begin{array}{c}\text { Mean diurnal } \\
\text { temperature range }\end{array}$ & $\begin{array}{c}\text { Mean relative } \\
\text { humidity }\end{array}$ & precipitation \\
\hline BDWF-MAM & $0.45^{*}$ & $-0.48^{*}$ & 0.20 & 0.23 & 0.01 \\
\hline
\end{tabular}

* Indicates that the correlation coefficients are significant at $99 \%$ confidence levels from the t-test. 
may mean that the continuous rising of the temperature in the sand-dust source and transmission path regions during cold seasons suppresses the occurrence of dust weather. Also, as mentioned above, the DTR is a possible index of atmospheric stability. High (low) DTR may represent unstable (stable) stratification to a certain degree. But, there are many complex factors that influence atmospheric stability. Thus, even though the BDWF-MAM over Baicheng is significantly correlated with the local DTR (with a $99 \%$ confidence level), it can also be poorly correlated with the DTR in the sand-dust source and transmission path regions. The BDWF-MAM over Baicheng is not well related to the mean $\mathrm{RH}$ and precipitation of the chosen 75 observation stations, especially at the inter-decadal scale.

The analysis above has given a relatively clear sense that the variation in the BDWF over Baicheng is more related to the variations in the wind force and surface air temperature in the sand-dust source and transmission path and local regions than the other climatic factors, especially at the inter-decadal scale. The weakening wind and temperature increase in the spring may suppress the occurrence of dust weather, and result in the BDWF decreasing over Baicheng. But, all of the climatic factors are just the suppressed or advanced conditions for dust weather, and their variations are not simple reason-result explanations for the variation of the BDWF over Baicheng. The variations in all of the climatic factors, including the DWF, may be jointly affected by the adjustments of large-scale circulations. Therefore, the variations in large-scale circulations will be briefly studied in the next section to discover the possible mechanisms of the DWF decreasing at the inter-decadal scale.

\subsection{Possible Causes for the Inter-Decadal Variation of the BDWF}

The differences of surface and 500-hPa air temperature from the period of $1986-2006$ minus those from the period of $1951-1985$ are shown in Fig. 6. They represent the inter-decadal variations of the surface and 500-hPa air temperature before and after the mid-1980s. It is not difficult to find that the surface air temperature rises almost uniformly over each of the selected areas, but the extent to which this occurs varies across regions. The SAT at the middle-high latitudes of Eurasia (such as Mongolia) increases more than those at the middle-low latitudes. The 500-hPa air temperature differences present a similar spatial pattern, but with the temperature increasing at high latitudes and decreasing at middle-low latitudes. The heterogeneous temperature variations at different latitudes may reduce the meridional temperature and pressure gradient and cause the decreasing of the cold air invading China and the reduction of the cyclone frequency in northern China (Qian et al. 2002; Zhu et al. 2008), which are the conditions for dust weather influencing China.
The variation in the steering current plays a critical role in the frequency of occurrences of cold air invading China during the cold seasons, as does the DWF in northern China. The inter-decadal variations in the geo-potential height and wind velocity at a $500-\mathrm{hPa}$ pressure level are investigated. The climatology (averaged for 1971 - 2000) and differences (1986 - 2006 minus 1951 - 1985) of the geo-potential height and wind velocity at $500-\mathrm{hPa}$ are shown in Fig. 7. For climatology, the Westerlies dominate the areas in Fig. 7a, with a trough existing almost along the eastern coastline of Eurasia Continent, which is called the East Asian Trough. The Westerlies at 500-hPa steer the cold air in the low troposphere which continuously influences China. But, for the inter-decadal variations, an anti-cyclone wind pattern exists at the middle-high latitudes of eastern Eurasia (Fig. 7b). It can be clearly seen that this anti-cyclone pattern weakened the dominating westerlies in southern Mongolia and northern China after the mid-1980s and corresponds to the sharp decrease in the BDWF over Baicheng after the mid-1980s. The zonal winds anomalies are consistent with the results shown by Zhu et al. (2008).

To study the inter-decadal variations of circulations in eastern Eurasia in more detail, vertical motions are also analyzed (Fig. 8). From the meridional section of the climatology (averaged for 1971 - 2000) of the vertical velocity in the Northern Hemisphere, which is averaged in the range of $90-120^{\circ} \mathrm{E}$, it can be clearly found that sinking motions dominate at the middle latitudes of the selected longitude range $\left(90-120^{\circ} \mathrm{E}\right)$, especially in the middle-low troposphere (Fig. 8a). Fig. 8b presents the differences (1986 - 2006 minus 1951 - 1985) of the vertical velocity averaged in the range of $90-120^{\circ} \mathrm{E}$. It is clear that the pattern of vertical velocity differences is similar to that of the climatology, with downward motions at the middle latitudes. This means that the sinking motions at the middle latitudes have strengthened over the past two decades. The strengthening downward motions may result in the westerly winds being reduced in the middle-low troposphere at the middle latitudes of eastern Eurasia, and the downward motions may also have some impact on the decrease of the DWF in northern China.

All of the discussions above regarding the inter-decadal variation in the circulation patterns refer to the spring. Overall, all of the variations, including the heterogeneous temperature rising, anti-cyclone wind pattern in the middle troposphere and the sinking motion increasing at the middle latitudes of eastern Eurasia in the past two decades, may produce similar effects, namely, the weakening of steering westerlies, a decrease in the cold air invading China and the reduction of cyclone occurrence in northern China, which are the suppressible conditions for the occurrence of dust weather. Actually, the temperature, horizontal winds and vertical movements are connected and interactive, and each of them is one aspect of large-scale adjustments in circulation. So, it may be concluded that the decreasing DWF in 
(a)

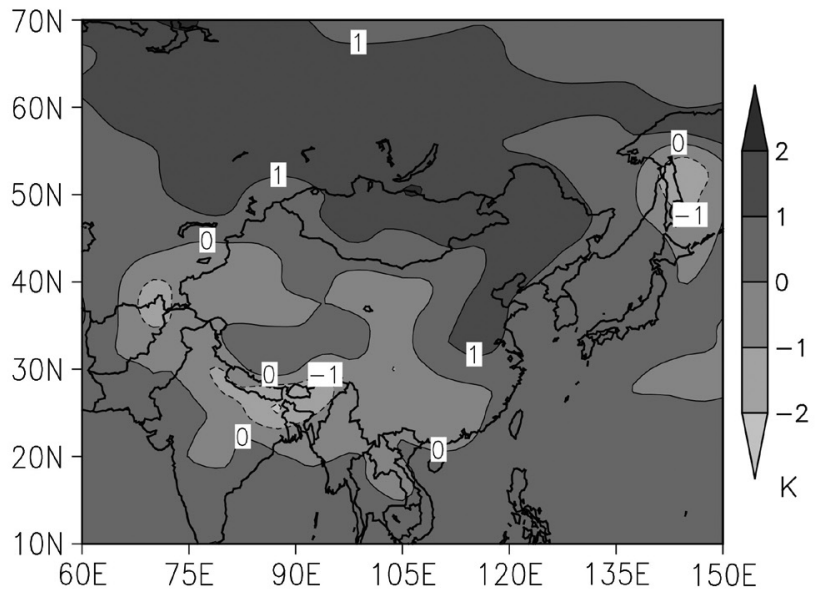

(b)

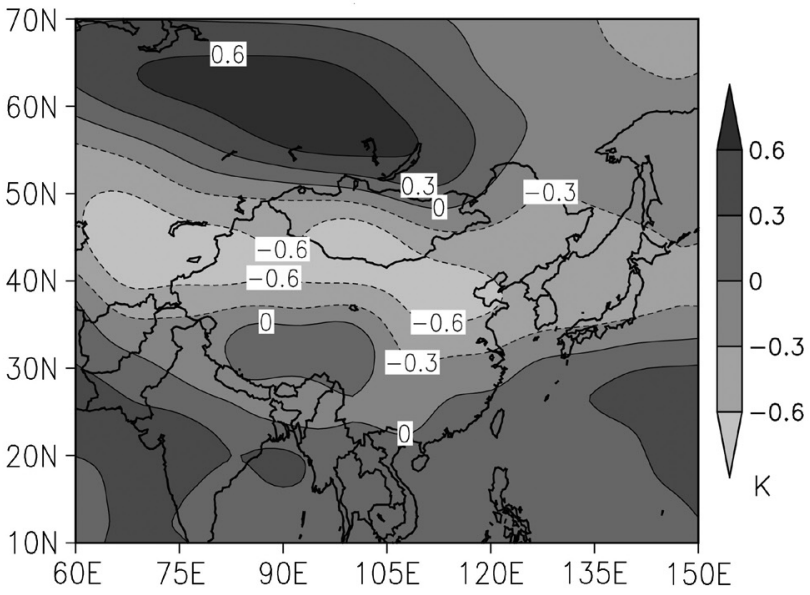

Fig. 6. Distributions of (a) surface air temperature and (b) air temperature at $500 \mathrm{hPa}$ differences (K) by 1986 - 2006 minus 1951 - 1985 in eastern Eurasia.

(a)

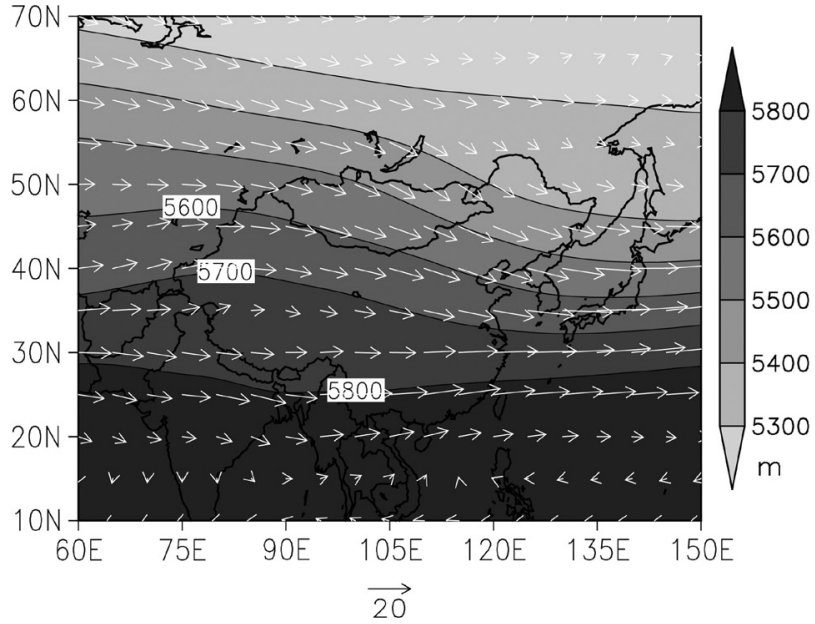

(b)

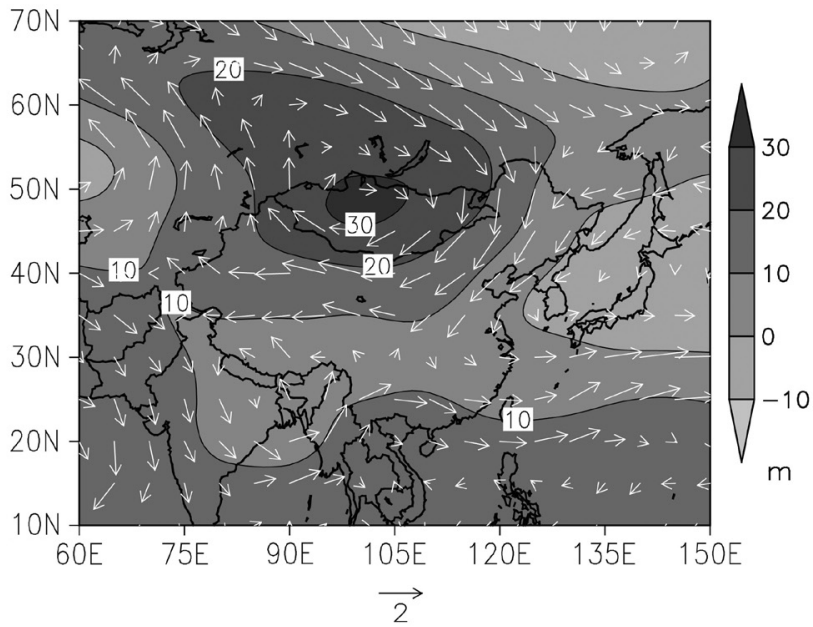

Fig. 7. (a) 500-hPa geo-potential height and horizontal wind field climatology (averaged for 1971 - 2000) and (b) their differences (1986 - 2006 minus 1951 - 1985) in eastern Eurasia. The units are gpm and $\mathrm{m} \mathrm{s}^{-1}$ for the geo-potential height and wind velocity, respectively.

(a)

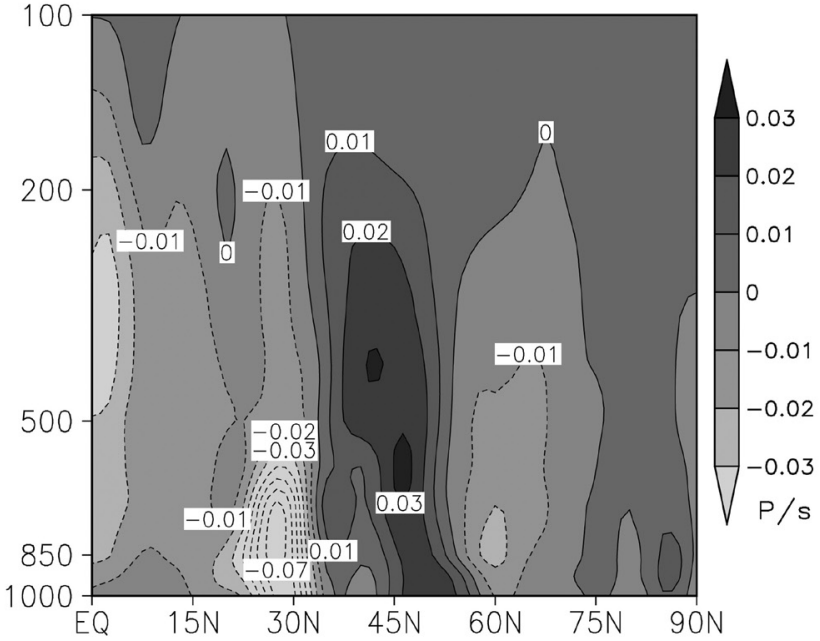

(b)

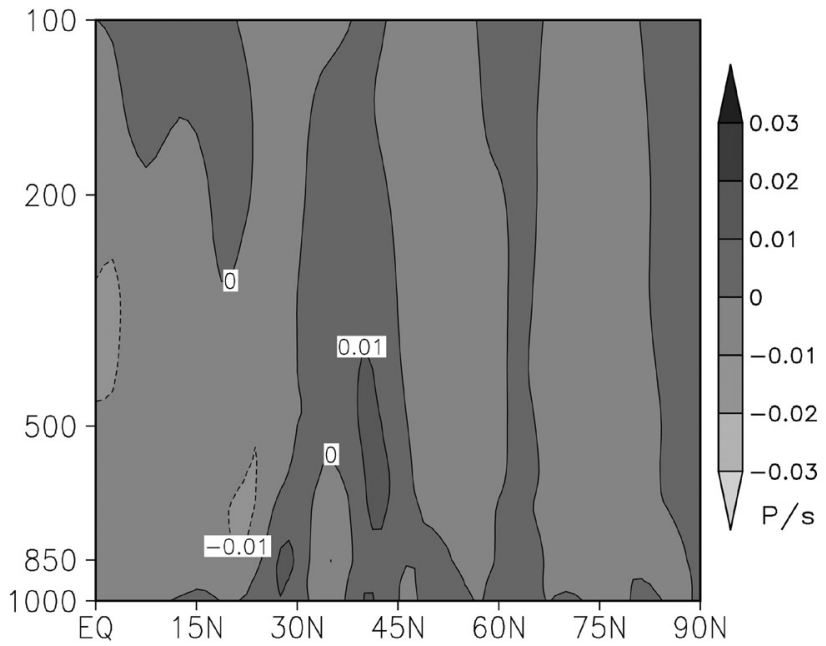

Fig. 8. Meridional section of (a) vertical velocity climatology (averaged for 1971 - 2000) and (b) its differences (1986 - 2006 minus 1951 - 1985$)$ in the Northern Hemisphere, averaged in the range of $90-120^{\circ} \mathrm{E}$. The unit of vertical velocity is Pascal s${ }^{-1}$. 
recent decades results from these adjustments of large-scale circulations in eastern Eurasia. The variations of these largescale circulations in eastern Eurasia may also be affected by variations of large-scale circulations in other areas, and even global-scale circulations, such as the North Atlantic Oscillation (NAO) maintaining positive phases, as well as El Niño and the Southern Oscillation (ENSO) becoming more frequent and stronger in recent decades (Hurrell 1995; Kumar et al. 1999). Moreover, Zhu et al. (2008) contributed the decrease of the westerly jet stream and the atmospheric baroclinicity in mid-latitude East Asia to the more warming trend around Lake Baikal (Zhu et al. 2008). The relationship among the variations of these large-scale circulations is not the emphasis of our research and so will not be discussed here.

\section{SUMMARY}

Blowing dust weather was the most typical dust weather over Baicheng and occurred frequently during the spring. The proportion of the BDWF during the spring as compared to the total could reach up to $75 \%$. The BDWF over Baicheng during the spring showed significant inter-decadal variability. The 1950s was the period that experienced blowing dust weather occurring with high frequency, whereas the BDWF decreased significantly after the mid-1980s.

The variability of some climatic factors over Baicheng during the spring was also studied, and it was found that the mean WS, DTR, RH and precipitation during the spring showed decreasing trends. Among them, the decreasing trends of the mean WS and DTR were significant at $99 \%$ confidence levels from the t-test, and the wind speed decreased sharply after the mid-1980s. The mean SAT escalated in a fluctuating manner during the period of 1951 2006.

The BDWF over Baicheng was well correlated with the local WS, SAT and DTR during the spring, and the CCs were $0.41,-0.47$ and 0.36 , respectively (all exceeding the 99\% confidence levels). The CCs between the BDWF over Baicheng and these selected climatic factors over the sanddust source and transmission path regions were also calculated, and it was found that the BDWF over Baicheng was well related with the mean WS and SAT in these sand-dust source and transmission path regions during the spring, with CCs being 0.45 and -0.48 , respectively. Weakening wind and increasing temperature during the cold seasons might be the suppressible conditions for the occurrence of dust weather and thereby result in the decreasing of the BDWF over Baicheng, especially its decreasing trend after the mid1980s.

Adjustments of large-scale circulations associated with decreasing meridional temperature differences, the weakening of steering westerlies and downward motion strengthening at the middle latitudes of eastern Eurasia in recent decades might be the causes of the BDWF over Baicheng dramatically decreasing after the mid-1980s. The variations in the large-scale circulations in eastern Eurasia might be affected by circulations in other critical areas, or even the globe, and determining the relationships among the variations in these large-scale circulations requires further and specific research.

Acknowledgements This research is supported by the Pilot Project of Knowledge Innovation Program of the Chinese Academy of Sciences (KZCX2-YW-Q11-03), the National Basic Research Program of China (2009CB723904, 2010CB428503), and the National Natural Science Foundation of China (40810059003).

\section{REFERENCES}

Cox, P. M., R. A. Betts, C. D. Jones, S. A. Spall, and I. J. Totterdell, 2000: Acceleration of global warming due to carbon-cycle feedbacks in a coupled climate model. Nature, 408, 184-187, doi: 10.1038/35041539. [Link]

Fan, K. and H. Wang, 2004: Antarctic oscillation and the dust weather frequency in North China. Geophys. Res. Lett., 31, L10201, doi: 10.1029/2004GL019465. [Link]

Fan, K. and H. Wang, 2007: Dust storms in North China in 2002: A case study of the low frequency oscillation. Adv. Atmos. Sci., 24, 15-23, doi: 10.1007/s00376-0070015-z. [Link]

Gao, Q. X., Z. H. Ren, Y. G. Zhang, Z. Q. Li, and C. R. Pubu, 2004: Dust event and its formation, development and transportation based on satellite data. Resour. Sci., 26, 24-29. (in Chinese)

Han, Z., H. Ueda, K. Matsuda, R. Zhang, K. Arao, Y. Kanai, and H. Hasome, 2004: Model study on particle size segregation and deposition during Asian dust events in March 2002. J. Geophys. Res., 109, D19205, doi: 10.1029/2004jd004920. [Link]

Hu, Y. Q. and Y. Mitsuta, 1997: Micrometeorological characteristics and local triggering mechanism of strong dust storm. Scientia Atmospherica Sinica, 21, 581-589. (in Chinese)

Hurrell, J. W., 1995: Decadal trends in the North Atlantic Oscillation: Regional temperatures and precipitation. Science, 269, 676-679, doi: 10.1126/science.269.5224. 676. [Link]

Jiao, M. Y., R. Y. Niu, L. N. Zhao, and H. Yan, 2004: Comparative analysis on causing factors of dust events. $J$. Desert Res., 24, 696-700. (in Chinese)

Kalnay, E., M. Kanamitsu, R. Kistler, W. Collins, D. Deaven, L. Gandin, M. Iredell, S. Saha, G. White, J. Woollen, Y. Zhu, A. Leetmaa, R. Reynolds, M. Chelliah, W. Ebisuzaki, W. Higgins, J. Janowiak, K. C. Mo, C. Ropelewski, J. Wang, R. Jenne, and D. Joseph, 1996: The NCEP/NCAR 40-year reanalysis project. Bull. 
Amer. Meteorol. Soc., 77, 437-471, doi: 10.1175/15200477(1996)077<0437:TNYRP>2.0.CO;2. [Link]

Kumar, K. K., B. Rajagopalan, and M. A. Cane, 1999: On the weakening relationship between the indian monsoon and ENSO. Science, 284, 2156-2159, doi: 10.11 26/science.284.5423.2156. [Link]

Lashof, D. A. and D. R. Ahuja, 1990: Relative contributions of greenhouse gas emissions to global warming. $\mathrm{Na}$ ture, 344, 529-531, doi: 10.1038/344529a0. [Link]

Li, L. J. and Q. X. Gao, 2001: Source analysis of Beijing sanddust in 2000. Res. Environ. Sci., 14, 1-3. (in Chinese)

Liu, J. T., X. G. Jiang, X. J. Zheng, L. Kang, and F. Y. Qi, 2004: An intensive Mongolian cyclone genesis induced severe dust storm. Terr. Atmos. Ocean. Sci., 15, 1019-1033.

Liu, R. X., J. S. Zhang, Z. J. Zheng, and S. H. Zhang, 2007: The relationship between dust weather in Beijing and snow cover in dust source areas. Clim. Environ. Res., 12, 374-380. (in Chinese)

Liu, S. C. and C. J. Shiu, 2001: Asian dust storms and their impact on the air quality of Taiwan. AAQR, 1, 1-8.

Qian, W., L. Quan, and S. Shi, 2002: Variations of the dust storm in china and its climatic control. J. Climate, 15, 1216-1229, doi: 10.1175/1520-0442(2002)015<1216: VOTDSI $>2.0 . \mathrm{CO} ; 2$. [Link]

Qiu, X. F., Y. Zeng, and Q. L. Miao, 2001: Temporal-spatial distribution as well as tracks and source areas of sanddust storms in China. Acta Geographica Sinica, 56, 316-322. (in Chinese)

Root, T. L., J. T. Price, K. R. Hall, S. H. Schneider, C. Rosenzweig, and J. A. Pounds, 2003: Fingerprints of global warming on wild animals and plants. Nature, 421, 57-60, doi: 10.1038/nature01333. [Link]

Shen, Z. X., J. J. Cao, R. Arimoto, R. J. Zhang, D. M. Jie, S. X. Liu, and C. S. Zhu, 2007: Chemical composition and source characterization of spring aerosol over Horqin sand land in northeastern China. J. Geophys. Res., 112, D14315, doi: 10.1029/2006JD007991. [Link]

Wang, X., J. Huang, M. Ji, and K. Higuchi, 2008: Variability of East Asia dust events and their long-term trend. Atmos. Environ., 42, 3156-3165, doi: 10.1016/j. atmosenv.2007.07.046. [Link]
Wang, Z., H. Ueda, and M. Huang, 2000: A deflation module for use in modeling long-range transport of yellow sand over East Asia. J. Geophys. Res., 105, 2694726959, doi: 10.1029/2000JD900370. [Link]

Wu, Y., R. Zhang, Z. Han, and Z. Zeng, 2010: Relationship between East Asian monsoon and dust weather frequency over Beijing. Adv. Atmos. Sci., 27, 1389-1398, doi: 10.1007/s00376-010-9181-5. [Link]

Zhang, R., Z. Han, M. Wang, and X. Zhang, 2002: Dust storm weather in China, New characteristics and origins. Quat. Sci., 22, 374-380. (in Chinese)

Zhang, R., R. Arimoto, J. An, S. Yabuki, and J. Sun, 2005: Ground observations of a strong dust storm in Beijing in March 2002. J. Geophys. Res., 110, D18S06, doi: 10. 1029/2004JD004589. [Link]

Zhang, R., C. Fu, Z. Han, and C. Zhu, 2008: Characteristics of elemental composition of PM2.5 in the spring period at Tongyu in the semi-arid region of Northeast China. Adv. Atmos. Sci., 25, 922-931, doi: 10.1007/s00 376-008-0922-7. [Link]

Zhang, R., Z. Han, T. Cheng, and J. Tao, 2009: Chemical properties and origin of dust aerosols in Beijing during springtime. Particuology, 7, 61-67, doi: 10.1016/j. partic.2008.11.003. [Link]

Zhang, X. L., Q. C. Li, P. Xie, Y. C. Wang, and H. J. Li, 2005: Features and causes of dust weather in recent years in Beijing. J. Desert Res., 25, 417-421. (in Chinese)

Zhang, Z. G., Y. H. Zhao, Y. L. Xue, W. L. Chen, Q. X. Gao, X. X. Yang, F. Q. Su, and Z. H. Ren, 2003: The relation between sand-dust weather in Beijing and meteorological conditions of dust source areas. J. Safety Environ., 3, 20-24. (in Chinese)

Zhou, Z. J., 2001: Blowing-sand and sandstorm in China in recent 45 years. Quat. Sci., 21, 9-17. (in Chinese)

Zhou, Z. and G. Zhang, 2003: Typical severe dust storms in northern China during 1954-2002. Chin. Sci. Bull., 48, 2366-2370.

Zhu, C., B. Wang, and W. Qian, 2008: Why do dust storms decrease in northern China concurrently with the recent global warming? Geophys. Res. Lett., 35, L18702, doi: 10.1029/2008GL034886. [Link] 